\author{
Marquette University \\ e-Publications@Marquette
}

Biomedical Engineering Faculty Research and

Publications

Biomedical Engineering, Department of

$9-15-1996$

\title{
Effective Doses of Recombinant Human Bone Morphogenetic Protein-2 in Experimental Spinal Fusion
}

\author{
Harvinder Sandhu \\ Cornell University Medical College \\ Linda E.A. Kanim \\ UCLA School of Medicine \\ J. Michael Kabo \\ UCLA School of Medicine \\ Jeffrey M. Toth \\ Marquette University, jeffrey.toth@marquette.edu \\ Erik N. Zeegen \\ UCLA School of Medicine
}

See next page for additional authors

Follow this and additional works at: https://epublications.marquette.edu/bioengin_fac

Part of the Biomedical Engineering and Bioengineering Commons

\section{Recommended Citation}

Sandhu, Harvinder; Kanim, Linda E.A.; Kabo, J. Michael; Toth, Jeffrey M.; Zeegen, Erik N.; Liu, David; Delamarter, Rick B.; and Dawson, Edgar G., "Effective Doses of Recombinant Human Bone Morphogenetic Protein-2 in Experimental Spinal Fusion" (1996). Biomedical Engineering Faculty Research and Publications. 569.

https://epublications.marquette.edu/bioengin_fac/569 


\section{Authors}

Harvinder Sandhu, Linda E.A. Kanim, J. Michael Kabo, Jeffrey M. Toth, Erik N. Zeegen, David Liu, Rick B. Delamarter, and Edgar G. Dawson 
Marquette University

e-Publications@Marquette

\section{Biomedical Engineering Faculty Research and Publications/College of Engineering}

This paper is NOT THE PUBLISHED VERSION; but the author's final, peer-reviewed manuscript. The published version may be accessed by following the link in the citation below.

Spine, Vol. 21, No. 18 (November, 2017): 2115-2122. Permalink. This article is (C) Lippincott Williams \& Wilkins, Inc. and permission has been granted for this version to appear in e-Publications@Marquette. Lippincott Williams \& Wilkins, Inc. does not grant permission for this article to be further copied/distributed or hosted elsewhere without the express permission from Lippincott Williams \& Wilkins, Inc.

\section{Effective Doses of Recombinant Human Bone Morphogenetic Protein-2 in Experimental Spinal Fusion}

Sandhu, Harvinder S.

Department of Orthopaedic Surgery and the UCLA Comprehensive Spine Center, UCLA School of Medicine, Los Angeles, CA

Kanim, Linda E.A.

Department of Orthopaedic Surgery and the UCLA Comprehensive Spine Center, UCLA School of Medicine, Los Angeles, CA

Kabo, J. Michael

Department of Orthopaedic Surgery and the UCLA Comprehensive Spine Center, UCLA School of Medicine, Los Angeles, CA

Toth, Jeffrey $M$.

Department of Orthopaedic Surgery, The Medical College of Wisconsin, Milwaukee, WI

Zeegen, Erik N. 
Department of Orthopaedic Surgery and the UCLA Comprehensive Spine Center, UCLA School of Medicine, Los Angeles, CA

Liu, David

Department of Orthopaedic Surgery, The Medical College of Wisconsin, Milwaukee, WI

Delamarter, Rick B.

Department of Orthopaedic Surgery and the UCLA Comprehensive Spine Center, UCLA School of Medicine, Los Angeles, CA

Dawson, Edgar G.

Department of Orthopaedic Surgery and the UCLA Comprehensive Spine Center, UCLA School of Medicine, Los Angeles, CA

\section{Keywords:}

bone induction; bone morphogenetic protein; dog; polylactic acid polymer; posterolateral fusion; recombinant human bone morphogenetic protein-2

\section{Abstract:}

Study Design Nineteen dogs underwent L4-L5 intertransverse process fusions with either $58 \mu \mathrm{g}, 115$ $\mu \mathrm{g}, 230 \mu \mathrm{g}, 460 \mu \mathrm{g}$, or $920 \mu \mathrm{g}$ of recombinant human bone morphogenetic protein-2 carried by a polylactic acid polymer. A previous study (12 dogs) compared $2300 \mu \mathrm{g}$ of recombinant human bone morphogenetic protein-2, autogenous iliac bone, and carrier alone in this model. All fusions subsequently were compared.

Objectives: To characterize the dose-response relationship of recombinant human bone morphogenetic protein-2 in a spinal fusion model.

Summary of Background Data: Recombinant osteoinductive morphogens, such as recombinant human bone morphogenetic protein-2, are effective in vertebrate diaphyseal defect and spinal fusion models. It is hypothesized that the quality of spinal fusion produced with recombinant human bone morphogenetic protein-2, above a threshold dose, does not change with increasing amounts of inductive protein.

Methods: After decortication of the posterior elements, the designated implants were placed along the intertransverse process space bilaterally. The fusion sites were evaluated after 3 months by computed tomography imaging, high-resolution radiography, manual testing, mechanical testing, and histologic analysis.

Results: As in the study using $2300 \mu \mathrm{g}$ of recombinant human bone morphogenetic protein-2, implantation of 58-920 $\mathrm{\mu g}$ of recombinant human bone morphogenetic protein-2 successfully resulted in intertransverse process fusion in the dog by 3 months. This had not occurred in animals containing autograft or carrier alone. The cross-sectional area of the fusion mass and mechanical stiffness of the L4-L5 intersegment were not dose-dependent. Histologic findings varied but were not related to 
rhBMP-2 dose. Inflammatory reaction to the composite implant was proportional inversely to the volume of the fusion mass.

Conclusions: No mechanical, radiographic, or histologic differences in the quality of intertransverse process fusion resulted from a 40-fold variation in dose of recombinant human bone morphogenetic protein-2.

Recombinantly produced osteoinductive molecules, such as human bone morphogenetic protein, have facilitated healing of middiaphysial defects and fusion of spinal segments in lower vertebrates. Doses of recombinant bone morphogenetic proteins ranging from $1.4 \mu \mathrm{g}$ to more than $2000 \mu \mathrm{g}$ have been tested in experimentally produced segmental long bone defects in rodents, rabbits, sheep, and dogs. $\frac{3,5,6,8,9,17,25}{A}$ a recent study using recombinant human bone morphogenetic protein-7 (rhBMP-7) in a rabbit ulnar nonunion model suggested that greater amounts of implanted protein resulted in greater early bone formation and a faster rate of healing.. However, radiographic findings by 8 weeks and histologic results by 12 weeks were similar in all ulnar defects implanted with doses above a threshold of $6.25 \mu \mathrm{g}$. All of these defects healed successfully, whereas ulnae implanted with less than the threshold amount of inductive protein failed to do so.

The relationship between BMP dose and the rate and character of intersegmental spinal fusion has not been well defined. The purpose of this investigation was to evaluate fusion characteristics associated with a logarithmic series of doses of recombinant human bone morphogenetic protein-2 (rhBMP-2) delivered by a porous polylactic acid polymer in a dog lumbar intertransverse process fusion model. A previous study at this institution showed that a dose of $2300 \mu \mathrm{g}$ of rhBMP-2 delivered by the same carrier was superior to autologous iliac crest bone graft for producing single-level lumbar arthrodesis. $\underline{16}$ Data from that study are included here for purposes of comparison.

\section{- Materials and Methods}

Design. Nineteen mature female beagles underwent L4-L5 intertransverse process fusions in this study (Table 1). Five doses of rhBMP-2 in a modified logarithmic schedule were tested. In a previous study with this model, five dogs were implanted with autogenous iliac crest graft, five were implanted with a $2300 \mu \mathrm{g}$ dose of rhBMP-2, and two were implanted with the carrier alone. The results from that study are included here for comparison. Neither internal fixation nor external immobilization was used in either investigation. All animals were killed 3 months after surgery. 


\begin{tabular}{lcc}
\hline Condition & rhBMP-2 Dose & \# Animals Treated \\
\hline Current Study & & \\
OPLA + rhBMP-2 & $58 \mu \mathrm{g}$ & 6 \\
OPLA + rhBMP-2 & $115 \mu \mathrm{g}$ & 4 \\
OPLA + rhBMP-2 & $230 \mu \mathrm{g}$ & 4 \\
OPLA + rhBMP-2 & $460 \mu \mathrm{g}$ & 2 \\
OPLA + rhBMP-2 & $920 \mu \mathrm{g}$ & 3 \\
Previous Study & & 5 \\
OPLA + rhBMP-2 & $2300 \mu \mathrm{g}$ & 2 \\
OPLA only & - & 5 \\
Autograft & - & 31 \\
Total & & \\
OPLA = open cell polylactic acid. rhBMP-2 = recombinant human bone \\
morphogenetic protein-2.
\end{tabular}

$\underline{\text { Table } 1}$

Materials. The delivery vehicle open cell polylactic acid (OPLA) was prepared from D,D-L,L-polylactic acid and macrostructured into an "open cell" network of interconnected voids. The dimensions of this 2.2 - $\mathrm{mL}$ rectangular strip were $12.0 \mathrm{~mm} \times 6.0 \mathrm{~mm} \times 30.0 \mathrm{~mm}$ (supplied by Sofamor Danek, Memphis, $\mathrm{TN}$; developed and manufactured by THM Biomedical, Minneapolis, MN).

The rhBMP-2 (manufactured and supplied by Genetics Institute, Andover, MA) was provided in freezedried form and reconstituted intraoperatively with sterile water. One milliliter of solution containing 58 $\mu \mathrm{g}, 115 \mu \mathrm{g}, 230 \mu \mathrm{g}, 460 \mu \mathrm{g}$, or $920 \mu \mathrm{g}$ of rhBMP-2 was added to each OPLA strip to produce the composite implant.

Subjects. The animals were obtained from a single breeder and screened for systemic disease and conditioned for at least 1 week before inclusion in the study.

Surgical Procedure. Under halothane anesthesia and endotracheal intubation, the posterior lumbar region was prepared in sterile fashion. Using a limited midline approach, the paraspinal musculature was retracted from the spinous processes, lamina, facet joints, and transverse processes. With the assistance of a localization radiograph, care was taken to avoid exposure of adjacent facet joints and transverse processes. The appropriate transverse processes, lamina, and facet joints were decorticated with a power burr (Dremel Moto- Tool, Model 395, Racine, WI) until punctate bleeding was observed. Osseous debris left by decortication was washed away thoroughly with copious irrigation. 
The composite implant was prepared by the surgical assistant and inserted by the surgeon, who was blinded to the condition of the implant. When autograft was used, tricortical portions of both iliac crests were harvested through the same incision and morselized to expose the cancellous surfaces. All implants were placed into the right and left posterolateral gutters in direct apposition to the decorticated transverse processes of L4 and L5. The implants were not in contact with the exposed lamina.

Routine closure of the dorsolumbar fascia, subcutaneous tissue, and skin was performed. Parenteral antibiotics (enrofloxacin, $2.5 \mathrm{mg} / \mathrm{kg}$, or cefazolin, $2.0 \mathrm{mg} / \mathrm{kg}$ ) were administered intraoperatively and postoperatively for 72 hours after surgery. No postoperative dressings or braces were applied. The animals were allowed unrestricted activity.

Computed Tomography Evaluation. With the animals under pentobarbital anesthesia (Nembutal, Abbott, Abbott Park, IL), computed tomography (CT) scans were obtained 2 and 3 months after surgery for all animals. Sections of the fusion site were graded qualitatively for bone formation and remodeling. Also, quantitative CT analysis was performed using a photo image analyzer (superfine pitch monitor, Image-1/AT software, University Imaging Corp., West Chester, PA) as follows: crosssectional bone area was measured in four specific axial images of the fusion site and in four anatomically matched axial images of the untreated L3 vertebral body. The axial images were selected based on known vertebral body landmarks consistently present in beagles. Estimation of new bone formation was accomplished by measuring the difference in cross-sectional bone area between images of the fusion site and images of anatomically corresponding sections of the L3 vertebral body (reference measures). The values were expressed as ratios to these reference measures.

Sacrifice. Three months after surgery, the animals were killed with $0.22 \mathrm{~mL} / \mathrm{kg}$ of Euth- 6 Veterinary Solution (Western Medical Supply Company, Arcadia, CA), and the lumbar spines were explanted.

Manual Testing. After explantation, the L4-L5 intervertebral segment was tested manually for motion. The intervertebral segment was graded a nonfusion if motion was detected in any plane. Absence of motion was considered sufficient evidence of fusion.

High-Resolution Radiographic Evaluation. Using the Faxitron imaging device (Field Emission Corporation, McMinnville, Oregon), a high-resolution radiograph was taken of the explanted lumbar spine in the coronal plane after cleaning of soft tissues (Kodak Industrex Film, 50 - $13 \times 18 \mathrm{~cm}$, \#5072392, exposure $\approx 30$ MA @ 3 minutes). A radiographically successful intertransverse process fusion was defined as complete and uninterrupted osseous bridging of the transverse processes bilaterally. Unilateral osseous bridging or facet or interlaminar bony union was not considered successful intertransverse process fusion.

Nondestructive Mechanical Testing. The mechanical tests were conducted on all but one specimen from each rhBMP-2 dose group. The testing consisted of manually applying pure torques and linear loads and then measuring the corresponding angular and linear displacements. The slope of the forcedisplacement curve at $45 \mathrm{~N}$ of applied force was used to calculate the stiffness in each mode. The measurements were conducted in the following modes: flexion-extension (sagittal plane), right and left 
lateral bending (coronal plane), and clockwise and counterclockwise rotation (axial plane). For each mode, the average of the median measures of stiffness for the two directions was used for analysis. The protocol for this testing has been described previously. $\underline{16}$

Histologic Analysis. After mechanical testing, the spinal motion segment was fixed in $10 \%$ neutral buffered formaldehyde solution and bisected sagittally for histologic analysis. Both halves of the spinal segment were dehydrated sequentially in 70\% alcohol for 2-3 days, 95\% alcohol for 2-3 days, two changes of $100 \%$ alcohol for $2-3$ days each, and xylene for 1 day.

The explants then were embedded in methylmethacrylate and sectioned on a diamond saw (Buehler Isomet, Lake Bluff, IL) to produce at least 10 sections of an approximate thickness of 100-200 $\mu \mathrm{m}$. One side of the bisected level was sectioned in the sagittal plane, whereas the other side was sectioned in the axial plane. This orientation was randomized.

Undeclacified sections of the explants from this study were imaged with copper k- $\alpha$-radiation at $20 \mathrm{kV}$ and $30 \mathrm{~mA}$ using a microradiography unit (Kristalloflex-2, Siemens, New York, NY) and spectroscopic film (Kodak, Rochester, NY). Sections were exposed for 12.5 minutes for each $100 \mu \mathrm{m}$ of thickness. These spectroscopic plates then were developed, fixed, and analyzed for ossification using standard optical microscopy.

Staining was performed after microradiography to determine the quality and quantity of osteogenesis. When de novo bone was present, the distinct histogenesis (e.g., enchondral or intramembranous osteogenesis) was noted as was the presence of woven or lamellar bone matrix. Finally, differential staining with basic fuchsin and toluidine blue-o was used to evaluate the histologic and cytologic host response to the implant. This included evaluating the presence or absence of an inflammatory response to the carrier, the amount and quality of bone present, and the interface between the new bone and the native host bone. After staining, all undecalcified sections and microradiographs were read by an orthopedic histopathologist in a blinded fashion.

Statistical Analysis. Qualitative manual testing data, radiographic data, and CT data were analyzed using Fisher's exact test. Analysis of variance (BMDP Statistical Software, 2 V, Los Angeles, CA) was applied to measures of stiffness. Group average stiffness was compared among rhBMP-2 doses (high vs. low) separately for each mode of motion: sagittal bending, coronal bending, and axial rotation. There was one grouping factor (dose of rhBMP-2). Pearson's correlation coefficient was used to characterize the relationships between variables of interest and dose of rhBMP-2. Logistic regression analysis was used to evaluate the relationship between radiographic fusion and dose of rhBMP-2 (SAS, Version 6, SAS Institute Inc., Cary, NC).

\section{Results}

\section{Surgery}

All animals tolerated the procedures well, and no perioperative deaths occurred. Postoperative infections developed in two dogs that had been implanted with $58 \mu \mathrm{g}$ of rhBMP-2, so they were 
excluded from the study. The dogs weighed between $8.60-12.50 \mathrm{~kg}$ (average, $10.49 \mathrm{~kg}$ ) and ranged in age from 1.09 to 2.28 years (mean age, 1.59 years) at the time of surgery.

\section{Computed Tomography}

Computed tomography images showed new bone formation at all sites implanted with rhBMP-2 by 2 months after surgery (Figure 1). There was scant evidence of peripheral cortices surrounding the fusion masses in any site by this time. There were no remarkable qualitative differences between specimens containing different doses of the inductive protein.

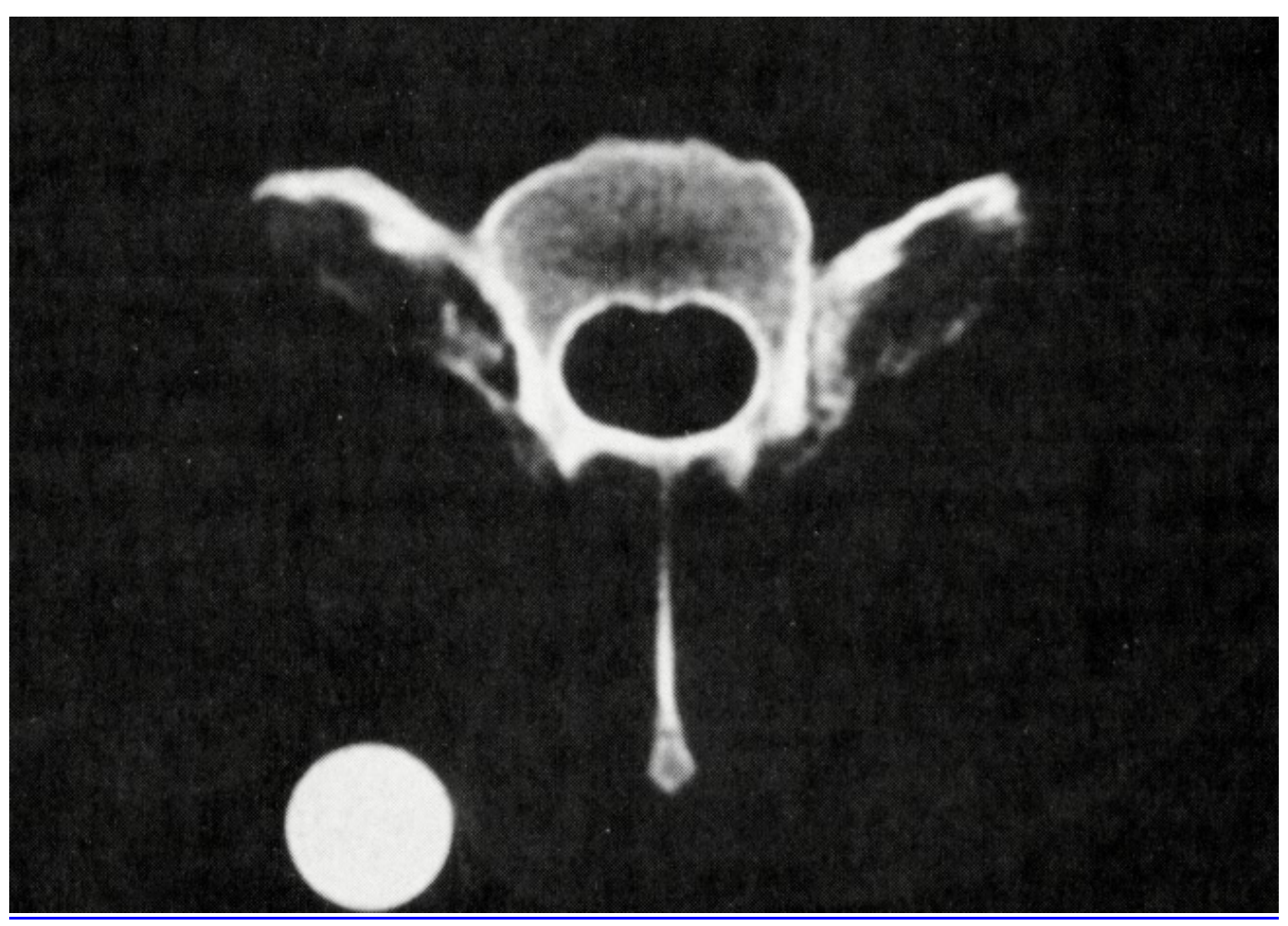

\section{Figure 1}

By 3 months, the presence of peripheral cortices was noted in several rhBMP-2 implanted sites (Figure 2). This remodeling was not related to the dose of the inductive protein. 


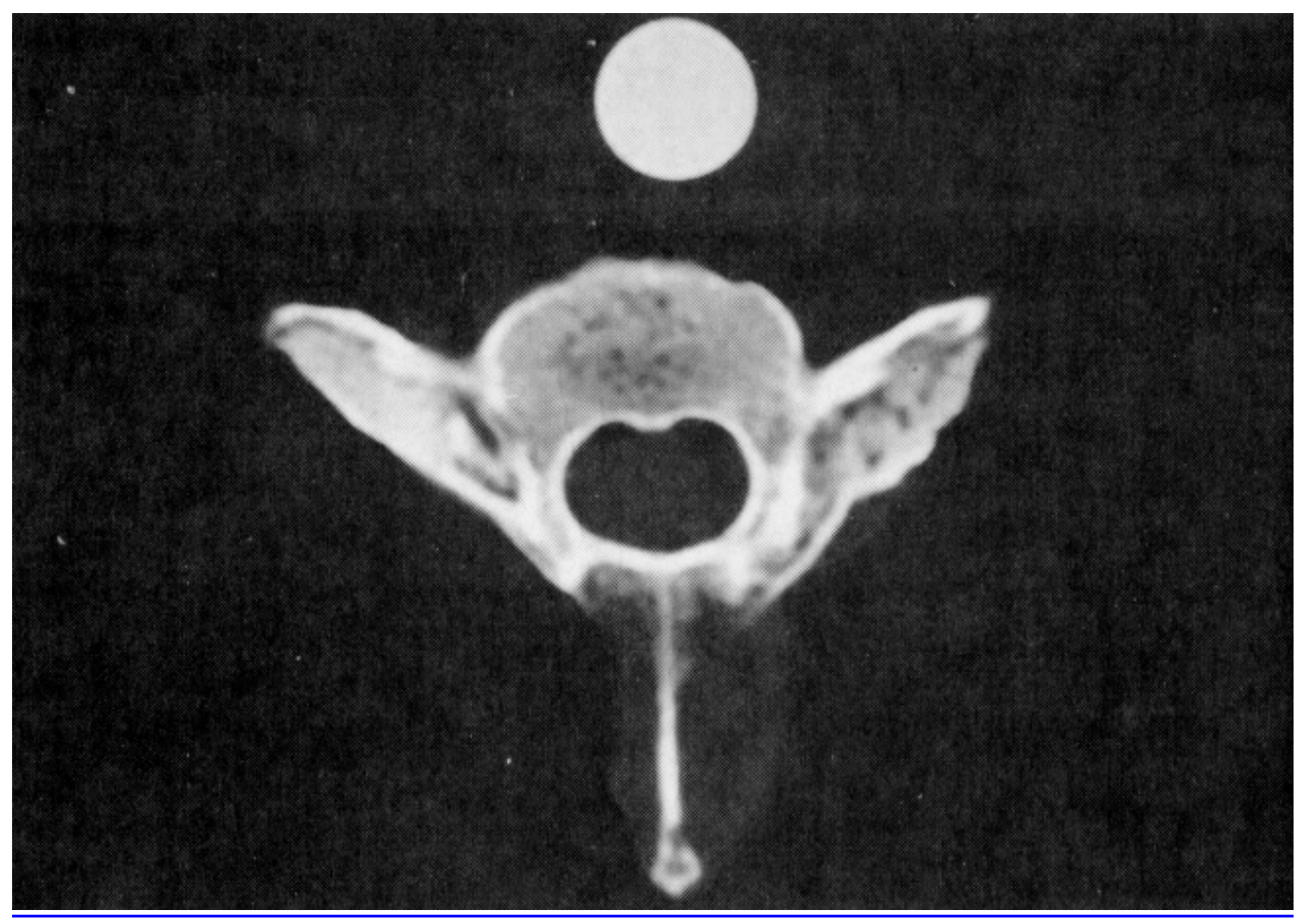

Figure 2

Quantitative CT analysis measuring new bone formation was performed on all fusion sites containing rhBMP-2. The findings are summarized in Table 2 and include data from the previous study. There were no differences in cross-sectional area of new bone regardless of the dose of rhBMP- 2 implanted $(P=0.84)$. 


\begin{tabular}{lcc}
\hline Condition & $n$ & $\begin{array}{c}\% \\
\text { Increase New Bone } \\
\text { (mean } \pm \text { SD) }\end{array}$ \\
\hline $\begin{array}{l}\text { Current Study } \\
\text { rhBMP-2 }(58 \mu \mathrm{g})\end{array}$ & $43 \pm 12$ \\
rhBMP-2 $(115 \mu \mathrm{g})$ & 4 & $51 \pm 13$ \\
rhBMP-2 $(230 \mu \mathrm{g})$ & 4 & $50 \pm 21$ \\
rhBMP-2 $(460 \mu \mathrm{g})$ & 4 & $45 \pm 16$ \\
rhBMP-2 $(920 \mu \mathrm{g})$ & 2 & $39 \pm 17$ \\
Previous Study & 3 & $52 \pm 15$ \\
rhBMP-2 $(2300 \mu \mathrm{g})$ & $-3 \pm 2$ \\
OPLA only & 5 & - \\
Autograft & 2 & \\
rhBMP-2 with OPLA carrier; ANOVA computed across all doses of rhBMP-2, \\
$\mathrm{F}$ (5) $=0.40, P=0.84$.
\end{tabular}

\section{$\underline{\text { Table } 2}$}

\section{High-Resolution Radiography}

Using the strict criteria for fusion described previously, radiographic fusion rates are depicted in $\underline{\text { Table }}$ 3. In the rhBMP-2 implanted sites, 14 (82\%) of 17 sites in the current study were fused radiographically. Two failures were noted in the lowest two dose groups (58 $\mu \mathrm{g}$ and $115 \mu \mathrm{g}$ ) and the third was in an intermediate group $(460 \mu \mathrm{g})$. All three of these spines actually were unilateral fusions but, according to the rating criteria, were considered failures. Using logistic regression analysis, however, no relationship was found between rhBMP-2 dose and radiographic fusion $(P=0.55 ; n=17)$. Examples of highresolution radiographs of spines containing rhBMP-2 implants can be seen in Figure 3. 


$\begin{array}{lc}\text { Current Study } & \\ \text { rhBMP-2 }(58 \mu \mathrm{g}) & 3 / 4 \\ \text { rhBMP-2 }(115 \mu \mathrm{g}) & 3 / 4 \\ \text { rhBMP-2 }(230 \mu \mathrm{g}) & 4 / 4 \\ \text { rhBMP-2 }(460 \mu \mathrm{g}) & 1 / 2 \\ \text { rhBMP-2 }(920 \mu \mathrm{g}) & 3 / 3 \\ \text { Previous Study } & \\ \text { rhBMP-2 }(2300 \mu \mathrm{g}) & 5 / 5 \\ \text { OPLA only } & 0 / 2 \\ \text { Autograft } & 0 / 5\end{array}$

rhBMP-2 = recombinant human bone morphogenetic protein- 2. OPLA $=$ open cell polylactic acid.

$\underline{\text { Table } 3}$

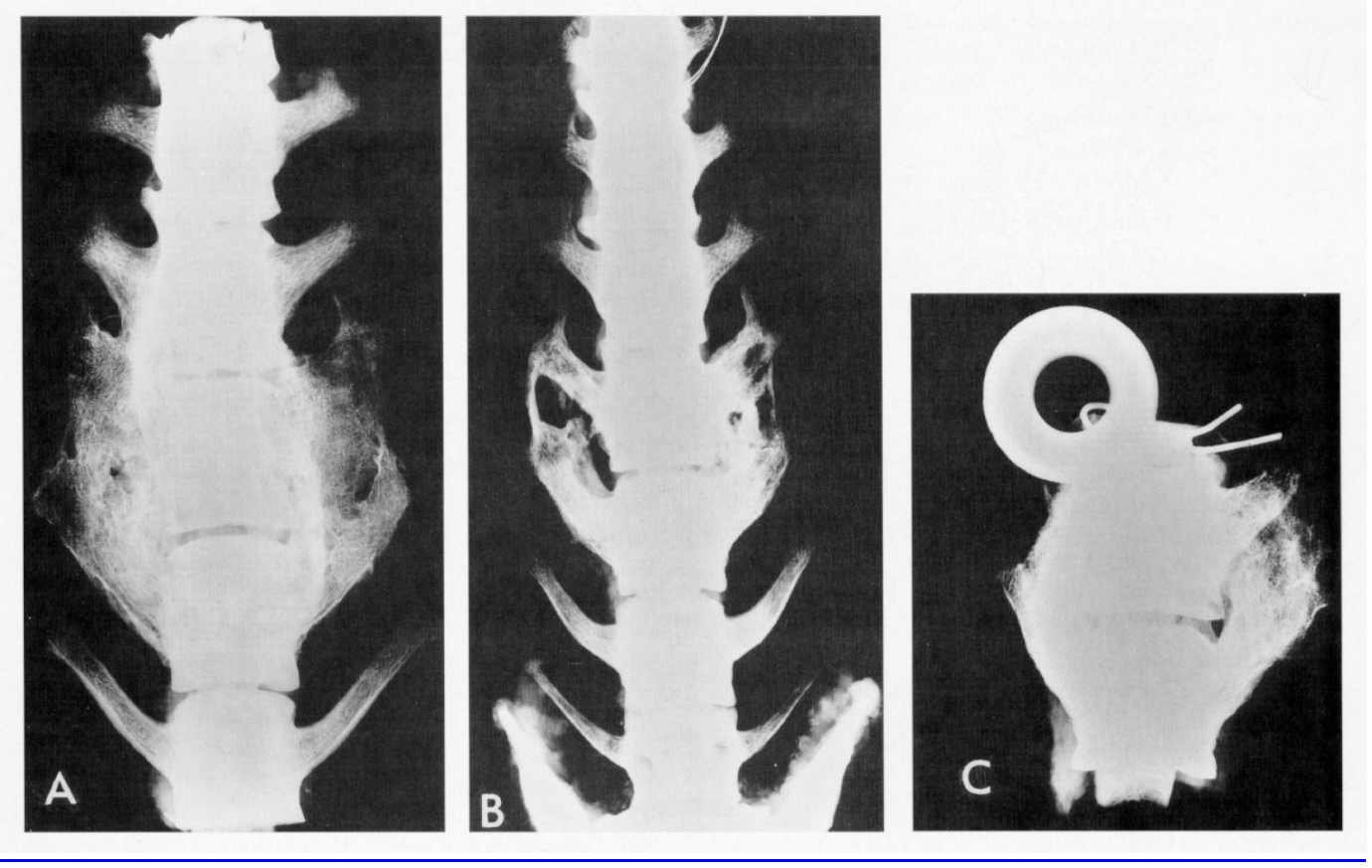

Figure 3 


\section{Manual Testing}

All spines implanted with rhBMP-2 composites, regardless of dose, achieved solid intersegmental fusion by manual motion testing (Table 4). No differences could be detected among rhBMP-2implanted sites.

Condition

\section{Current Study} rhBMP-2 $(58 \mu \mathrm{g})$

rhBMP-2 $(115 \mu \mathrm{g})$

rhBMP-2 $(230 \mu \mathrm{g})$

rhBMP-2 $(460 \mu \mathrm{g})$

rhBMP-2 $(920 \mu \mathrm{g})$

Previous Study

rhBMP-2 $(2300 \mu \mathrm{g})$

OPLA only

Autograft
Manual Fusions

(number/total)

rhBMP-2 = recombinant human bone morphogenetic protein-2. OPLA = open cell polylactic acid.

\section{Table 4}

\section{Mechanical Testing}

Mechanical testing was performed on all specimens regardless of the presence or absence of intertransverse process bridging. This was done to incorporate effects of facet arthrodesis that have been reported in dog models after decortication. $\underline{4}$ Median values for stiffness for each mode of testing were compared. There were no significant differences in mechanical stiffness among the dose groups of rhBMP-2 (sagittal bending, $P=0.38$; coronal bending, $P=0.34$; axial torque, $P=0.42$ ). There was no correlation between dose and stiffness of fusion in any of the three planes of motion (sagittal bending, $P=0.99$; coronal bending, $P=0.45$; axial torque, $P=0.39$ ).

\section{Histologic Examination}

Several specimens that had been implanted with the rhBMP-2 and OPLA carrier composite exhibited remnants of the polymeric delivery vehicle (Figure 4). The amount of undegraded polymer was not related to the dose of rhBMP-2 that was used. There appeared to be no relationship between the degree of inflammatory response and the dose of rhBMP-2. However, when abundant bone formation and a large fusion mass occurred, little to no inflammatory response was observed. When a large 
fusion mass did not occur, a low grade chronic inflammatory response consisting of multinucleated giant cells and round cells was observed.

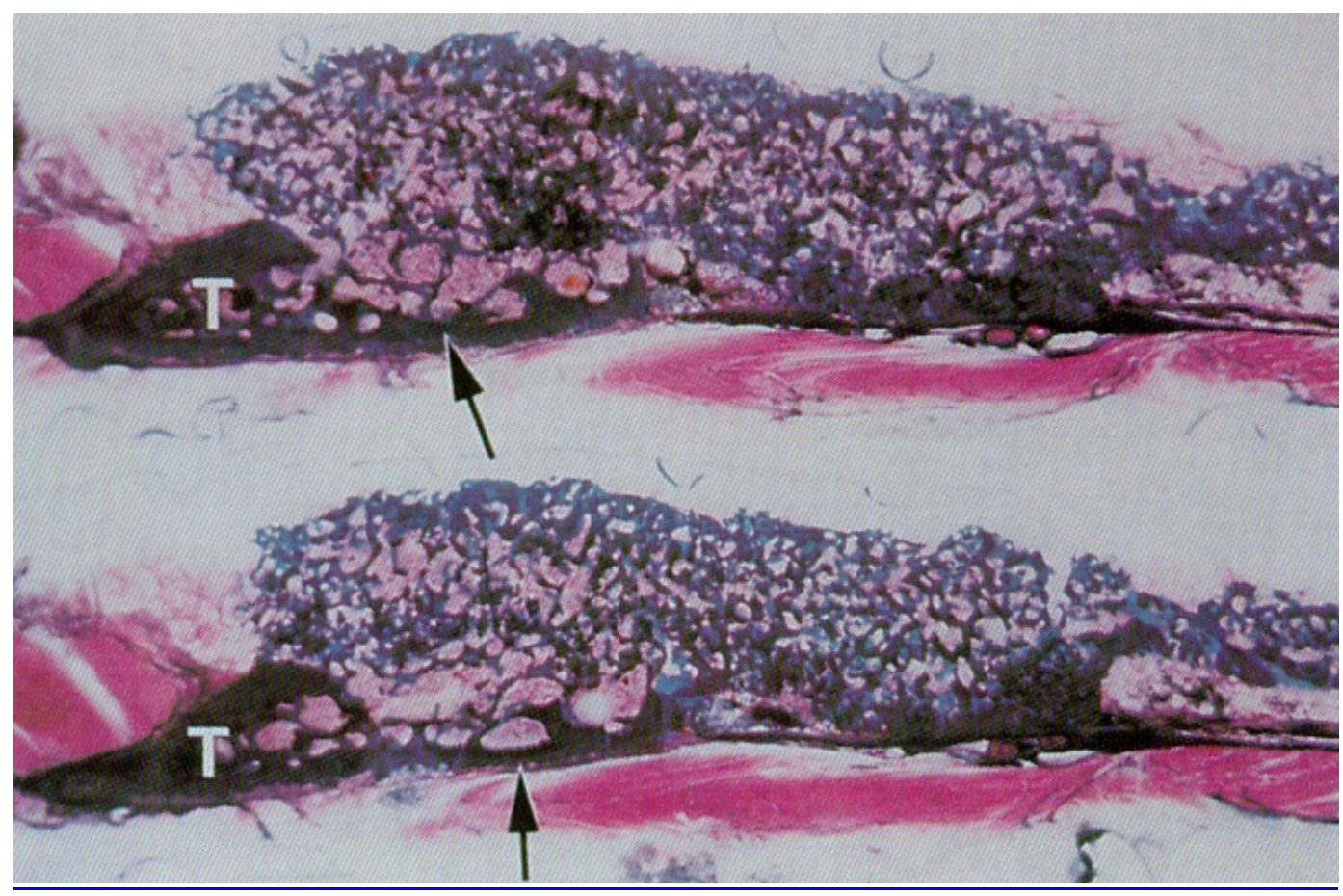

Figure 4

Varying quantities of de novo bone were noted in all specimens containing rhBMP-2 (Figure 5). Grossly and microscopically, no intrusion of de novo bone was noted in the spinal canal. Lamellar and woven bone trabeculae were seen with scattered areas of cortical remodeling. The overall amount of de novo bone, the ratio of lamellar to woven bone, and the degree of cortical remodeling could not be correlated with the dose of rhBMP-2. There was as much qualitative difference in bone formation between animals containing the same dose as there was between animals containing different doses. 


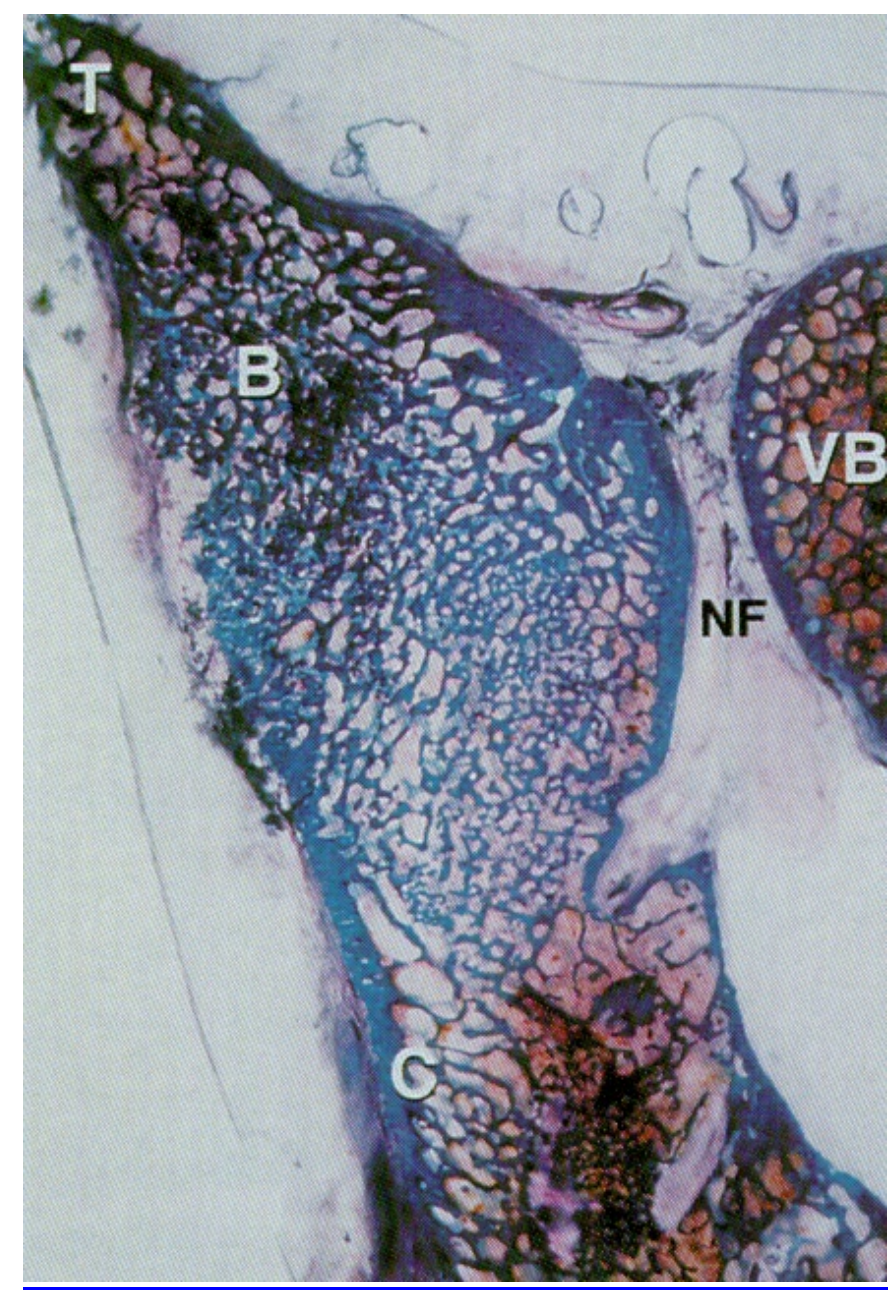

\section{Figure 5}

\section{- Discussion}

Bone morphogenetic protein constitutes less than $0.01 \%$ of total bone protein and less than $0.001 \%$ of the wet weight of marrow-free compact bone. $\frac{19-21}{}$ Before the successful cloning and expression of recombinant forms of osteoinductive proteins, relatively large amounts of diaphysial cortical (compact) bone had been required to extract useful amounts of BMP-containing protein aggregates. $\underline{18}$ For example, Wang et al $\underline{22}$ estimated a yield of $20 \mu \mathrm{g}$ of highly purified $(300,000$-fold) osteoinductive preparation per $10 \mathrm{~kg}$ of bovine bone, and because even highly purified fractions contain a mixture of osteogenic and nonosteogenic matrix proteins, accurate dose-response relationships had been difficult to ascertain. Further, osteogenic activity is known to be influenced by nonspecific and specific immune reactions to these protein aggregates. Thus, the relatively low activity of crude bone extracts had been attributed to immunogenic but nonosteogenic components of the extract. $\underline{1}$

The derivation and expression of cDNA clones of specific BMPs have permitted precise quantitation of the action of these molecules. Recombinantly produced protein preparations essentially contain 
singular molecular species (roughly $90 \%$ pure). Consequently, the measures of inductive protein contained within implants are more exact, and dose-response studies are more valid. Further, because members of the BMP family of proteins have been highly conserved (genetically consistent) for approximately 600 million years, they exhibit virtually no species specificity. ${ }^{8,24}$ Immunogenic influences on osteogenic activity, consequently, are minimal. Finally, because gene-cloning technology enables mass production of these proteins, evaluation of a broad spectrum of doses is feasible.

Recent in vivo ectopic bone-forming assays have suggested that volume of early bone formation is related linearly to dose of recombinant BMP. $\underline{23}$ However, efficacy studies in specific applied clinical models have not shown, above a defined threshold dose, that the rate or quality of clinical success is related to the actual dose. $\underline{5}$

In this study, all sites implanted with rhBMP-2 achieved clinical arthrodesis by 3 months after implantation. This was true despite a 40 -fold variation between the highest and lowest doses tested. Compared with the results using autogenous iliac bone graft from the previous study (Tables 3,4 ), all rhBMP-2-containing implants were associated with clearly superior clinical and radiographic results (manual testing: all rhBMP-2 conditions greater than autograft, $P<0.001$; radiographic testing: all rhBMP-2 conditions greater than autograft, $P<0.001)$. Even the lowest dose within this range was more effective than was iliac crest graft for generating intersegmental fusion within 3 months. Additional data from the authors' laboratory on two dogs have shown successful clinical fusion with autogenous iliac crest graft in this model when the animals were maintained for 6 months. $\frac{15}{1 t}$ appears that successful intertransverse process fusions occur with autograft in this model, albeit not as rapidly as compared with rhBMP-2 implants. The differences were particularly significant at the 3-month timepoint.

Of three dogs implanted with rhBMP-2 that did not satisfy strict radiographic criteria for fusion (bilateral intertransverse process bridging), two belonged to the lowest two dose groups. Both animals exhibited unilateral unions. These findings were not statistically significant, and moreover, when mechanically tested, the fusions obtained in these animals were neither different from other fusions within these groups nor from fusions obtained with higher doses of rhBMP-2. Combining the data from this study and previous data with this model, the authors cannot conclude that there are differences in the rates of clinical and radiographic fusion produced with 58-2300 $\mu \mathrm{g}$ doses of rhBMP-2 (manual testing, all fused; radiographic testing, $P=0.38$ ). However, the presence of radiographic "failures" with the lowest doses suggests that the lower end of this range of doses may be approaching the minimum effective dose. This may be better elucidated with an increased sampling size at these lower doses.

When characterizing the quality of fusion in terms of mechanical stability, no relationship was noted between fusion stiffness and rhBMP-2 dose in either sagittal, coronal, or axial planes of motion. When combined with previous data, still no significant relationship between fusion stiffness and dose was noted (sagittal bending, $P=0.48$; coronal bending, $P=0.11$; axial torque, $P=0.06$ ). The data again were compared after mechanical testing results were reassigned to "high dose" (2300 $\mu \mathrm{g})$, "low dose" (58$920 \mu \mathrm{g})$, autograft, and carrier-only groups. The comparisons are summarized in Table 5 . Both high-and low-dose rhBMP-2 sites had resultant fusions with greater stiffness than did autografted sites in all planes of motion (axial torque, $P<0.001, P<0.001$; sagittal bending, $P<0.02, P<0.01$; and coronal 
bending, $P<0.04, P<0.02)$. High-dose implanted sites were not different from low-dose implanted sites in stiffness to sagittal and coronal bending $(P=0.42, P=0.19)$. High-dose sites did exhibit greater stiffness to axial torque testing compared with low-dose sites $(P=0.03)$. However, because this was noted only in one plane of motion and a significant linear relationship was not observed when the doses were separated, the authors do not believe that these data confirm a qualitative difference in strength of fusion. Moreover, evidence that there were no differences in cross-sectional new bone formation between the different dose groups as determined by quantitative CT analysis further argues that the fusions were similar qualitatively.

\begin{tabular}{|c|c|c|c|}
\hline Condition & $\begin{array}{c}\text { Sagittal } \\
\text { Bending }(\mathrm{N} / \mathrm{cm})\end{array}$ & $\begin{array}{c}\text { Coronal } \\
\text { Bending }(\mathrm{N} / \mathrm{cm})\end{array}$ & $\begin{array}{c}\text { Axial } \\
\text { Torque } \\
\left(\mathrm{Nm} /{ }^{\circ}\right)\end{array}$ \\
\hline & Mean $\pm S D$ & Mean $\pm S D$ & Mean $\pm S D$ \\
\hline Current Study & & & \\
\hline $\begin{array}{l}\text { rhBMP-2 }(58-920 \mu \mathrm{g}) \\
\text { Previous Studv }\end{array}$ & $161 \pm 57$ & $228 \pm 109$ & $2.9 \pm 0.9$ \\
\hline rhBMP-2 $(2300 \mu \mathrm{g})$ & $193 \pm 88$ & $139 \pm 28$ & $4.1 \pm 0.5$ \\
\hline OPLA only & $81(-)$ & $44(-)$ & $0.6(-)$ \\
\hline Autograft & $78 \pm 18$ & $89 \pm 31$ & $0.9 \pm 0.3$ \\
\hline
\end{tabular}

\section{$\underline{\text { Table } 5}$}

Histologically, abundant bone formation had been noted in all specimens containing the inductive protein. No overt qualitative differences in fusion mass associated with the current spectrum of doses could be detected. Rather vigorous bone formation was seen despite a low rhBMP-2 dose in some animals, whereas less bone formation was seen occasionally in high-dose implanted sites. In addition, there was no relationship between the degree of remodeling or the presence of remnant polymer, and the dose of the inductive protein.

In the previous study, a chronic foreign body response consisting of multinucleated giant cells, histiocytes, and pyknotic mononuclear round cells was seen in sites that had been implanted with OPLA carrier only. $\frac{16}{}$ In this study, a low-grade chronic inflammatory response also was noted in several specimens that contained OPLA with rhBMP-2 but was far less than the reaction observed when OPLA was used alone. Interestingly, the inflammatory response to the composite implant inversely was proportional to the abundance of the fusion mass and not to the dose of the rhBMP-2. It is possible that this is related to a limited population of inducible stem cells. Thus, rapid recruitment of stem cells to boneforming cells may limit the number of cells available for an inflammatory response. Conversely, 
the presence of an early inflammatory response may limit the number of stem cells available for osteoinduction, thereby altering subsequent osteogenesis. Stem cell lineage studies currently are in progress and may provide useful information in the near future.

The events of the biologic response to rhBMP-2 in vivo are complex and may be influenced by several variables. The timecourse of activity of rhBMP-2 in the bone formation process, the location of its target cell, and its interactions with other growth factors are subjects of current research. $.11,12,18$ Certainly, the influence of the delivery vehicle cannot be overemphasized. Osteoinductive molecules such as rhBMP-2, when implanted alone, are cleared rapidly from the circulation and are ineffective. Lucas et al $\underline{10}$ and other have suggested that optimal delivery of inductive proteins requires controlled release, adequate exposure of the protein to the inducible target cells, ease of ingrowth of host tissue into the carrier, biocompatibility of the carrier, and resorption or incorporation of the implant into newly formed bone.

An open-cell polylactic acid polymer was used exclusively as the delivery vehicle in this study. The measured efficacy of rhBMP-2 in this model, consequently, is a reflection of this carrier's ability to satisfy the previously mentioned requirements. Biocompatibility of polylactic acid polymers has been of concern in previous studies,,$\frac{13,14}{1}$ and the presence of an immune response could be expected to influence the activity of the inductive protein. A prominent foreign body reaction was noted in the previous study when the polymeric delivery vehicle was implanted alone and was subdued in this study when the carrier was combined with the osteoinductive protein. The effect of even the low-grade inflammatory processes on the osteoinductivity of rhBMP-2 is unresolved. A similar relation between efficacy and dose would not necessarily be observed if another delivery vehicle such as fibrillar collagen, insoluble noncollagenous protein, or biocompatible ceramic were used. This model currently is being used to investigate some of these alternative delivery vehicles.

There is some evidence, although inconclusive, that more evolved animals may have a relative lack of inducible cells outside the skeleton. $\underline{\underline{2}}$ The activity of rhBMP- 2 in nonhuman primates currently is the subject of considerable interest. In this regard, it remains to be seen whether dosing data gathered from lower vertebrate models such as this can be appropriately extrapolated for use in humans. Nonetheless, the intent of this investigation was to characterize the relation between dosage of rhBMP-2 and clinical efficacy in an applied spinal fusion model. Previous studies on long bone defects in lower vertebrate models have suggested that, above a minimal threshold dose, the clinical effectiveness of rhBMP- 2 remains relatively consistent. In this study, the similarity of the fusions obtained across a 40-fold range of doses suggests that such a relationship may exist for dog spinal fusions.

\section{Conclusion}

Above a minimum threshold dose, fusions produced in lower vertebrates with recombinant osteoinductive morphogens, such as rhBMP-2, do not vary with increasing dose. Variables such as the delivery vehicle, surgical technique, and evolutionary status of the recipient may be more pertinent. Further studies examining these factors would be beneficial. 


\section{Acknowledgments}

The authors thank John Brekke, DDS, THM Biomedical Inc., for his scientific consultation regarding OPLA; Jennifer Smith, PhD, and John Wozney, PhD, Genetics Institute, Inc., for scientific consultation regarding rhBMP-2; the staff of the UCLA vivarium for excellent animal care; and senior undergraduate student Cindy Luppen for her assistance in the preparation of this manuscript.

\section{References}

1. Aldinger G, Herr G, Kusswetter W, Reis HJ, Thielemann FW, Holz U. Bone morphogenetic protein: A review. Int Orthop (SICOT) 1991;15:169-77.

2. Aspenberg P, Wang E, Thorngren KG. Bone morphogenetic protein induces bone in the squirrel monkey, but bone matrix does not. Proc Orthop Res Soc 1993;39:101.

3. Bostrom MPG, Tomin E, Lane JM, et al. The use of recombinant bone morphogenetic protein (rhBMP-2) in the rabbit ulnar non-union model: a radiographic, biomechanical and histological dose response study. Clin Orthop; in press.

4. Callewart CC, Kanim LEA, Seeger LL, Dawson EG. Variable fusion rates in the canine model. Presented at the 29th Annual Meeting of the Scoliosis Research Society, Portland, Oregon, September 23, 1994.

5. Cook SD, Baffes GC, Wolfe MW, Sampath TK, Rueger DC, Whitecloud III TS. The effect of recombinant human osteogenic protein-1 on healing of large segmental bone defects. J Bone Joint Surg [Am] 1994; 76:827-38.

6. Cook SD, Dalton JE, Tan EH, Whitecloud III TS, Rueger DC. In vivo evaluation of recombinant human osteogenic protein (rhOP-1) implants as a bone graft substitute for spinal fusions. Spine 1994;19:1655-63.

7. Ferguson D, Davis WL, Urist MR, Hurt WC, Allen EP. Bovine bone morphogenetic protein (bBMP) fraction-induced repair of craniotomy defects in the rhesus monkey (Macaca speciosa). Clin Orthop 1987;219:251-6.

8. Gerhart TN, Kirker-Head CA, Kriz MJ, et al. Healing segmental femoral defects in sheep using recombinant human bone morphogenetic protein. Clin Orthop 1993;293:317-26.

9. Lee SC, Shea M, Battle MA, et al. Healing of large segmental defects in rat femurs is enhanced by rhBMP-2 in a PLGA matrix: A torsional and densitometric assessment. Proc Orthop Res Soc 1994;40:206.

10. Lucas PA, Syftestad GT, Goldberg VM, Caplan Al. Ectopic induction of cartilage and bone by watersoluble proteins from bovine bone using a collagenous delivery vehicle. J Biomed Mater Res 1989;23:23-39.

11. Luyten FP, Cunningham NS, Vukicevic S, Paralkar V, Ripamonti U, Reddi AH. Advances in osteogenin and related bone morphogenetic proteins in bone induction and repair. Acta Orthop Belg 1992;58(Suppl 1):263-8. 
12. Lyons KM, Pelton RW, Hogan BLM. Patterns of expression of murine Vgr-1 and BMP-2a RNA suggest that transforming growth factor-beta-like genes coordinately regulate aspects of embryonic development. Genes Dev 1989;3:1657-68.

13. Miyamoto S, Takaoka K, Okada T, et al. Evaluation of polylactic acid homopolymers as carriers for bone morphogenetic protein. Clin Orthop 1992;278:274-86.

14. Saitoh H, Takata T, Nikai H, Shintani H, Hyon SH, Ikada Y. Effect of polylactic acid on osteoinduction of demineralized bone: Preliminary study of the usefulness of polylactic acid as a carrier of bone morphogenetic protein. J Oral Rehabil 1994;21:431-8.

15. Sandhu HS. UCLA School of Medicine, Los Angeles, California (unpublished data).

16. Sandhu HS, Kanim LEA, Kabo JM, et al. Evaluation of rhBMP-2 with an OPLA carrier in a canine posterolateral (transverse process) spinal fusion model. Spine 1995;20:2669-82.

17. Simmons DJ, Calhoun JH, Zimmerman B, Brantley J, Mader JT. Effect of recombinant human bone morphogenetic protein (rhBMP-2) on the healing of cortical bone in the rabbit tibia. Proc Orthop Res Soc 1994;40:507.

18. Urist MR. The search for and discovery of bone morphogenetic protein (BMP). In: Urist MR, O'Conner BT, Burwell RG, eds. Bone Grafts, Derivatives and Substitutes. London: Butterworth Heinemann, 1994:315-62.

19. Urist MR, Huo YK, Brownell AG, et al. Purification of bovine bone morphogenetic protein by hydroxyapatite chromatography. Proc Natl Acad Sci U S A 1984;81:371-5.

20. Urist MR, Lietze A, Dawson EG, Finerman GAM. Bone morphogenetic protein (BMP) delivery system. Presented at the 11th Annual Meeting of the Society for Biomaterials, San Diego, California, April 25-28, 1985.

21. Urist MR, Mikulski A, Lietze A. Solubilized and insolubilized bone morphogenetic protein. Proc Natl Acad Sci U S A 1979;76:1828-32.

22. Wang EA, Rosen $V$, Cordes $P$, et al. Purification and characterization of other distinct bone-inducing factors. Proc Natl Acad Sci U S A 1988;85:9484-8.

23. Wang EA, Rosen V, D'Alessandro JS, et al. Recombinant human bone morphogenetic protein induces bone formation. Proc Nat Acad Sci U S A 1990;87:2220-4.

24. Wozney JM. The bone morphogenetic protein family and osteogenesis. Mol Reprod Dev 1992;32:160-7.

25. Yasko AW, Lane JM, Fellinger EJ, Rosen V, Wozney JM, Wang EA. The healing of segmental bone defects, induced by recombinant human bone morphogenetic protein (rhBMP-2). J Bone Joint Surg [Am] 1992;74:659-70. 